\title{
Impact of Distance in the Provision of Maternal Health Care Services and Its Accountability in Murarai-II Block, Birbhum District
}

\author{
Alokananda Ghosh ${ }^{+*}$ and Biswaranjan Mistri ${ }^{\top}$
}

\begin{abstract}
The maternal health issue was a part of the Millennium Development Goals (MDGs, Target-5). Now it has been incorporated into Target-3 of 17 points Sustainable Development Goal-2030, declared by the United Nations, 2015. In India, about 50\% of newborn deaths can be reduced by taking good care of the mother during pregnancy, childbirth and postpartum period. This requires timely, well-equipped healthcare by trained providers, along with emergency transportation for referral obstetric emergency. Governments need to ensure physicians in the rural underserved areas. The utilisation of maternal healthcare services (MHCSs) depends on both the availability and accessibility of services along with accountability.

This study is based on an empirical retrospective survey, also called a historic study, to evaluate the influences of distance on the provision of maternal health services and on its accountability in Murarai-II block, Birbhum District. The major objective of the study is to identify the influence of distance on the provision and accountability of the overall MHCSs. The investigation has found that there is a strong inverse relationship $(-0.75)$ between accessibility index and accountability score with $p$-value $=<0.05$, where the direct connectivity index seem to have no direct influence on the accountability score (as the ' $r$ ' is 0.56 and $p$-value $=>0.05$ ). Tracking of pregnant women, identification of high risk pregnancy and timely Postnatal Care (PNC) have become the dominant factors of the maternal healthcare services in the first Principal Component Analysis (PCA), explaining $49.67 \%$ of the accountability system. Overall, institutional barriers to accessibility are identified as important constraints behind lesser accountability of the services, preventing the anticipated benefit. This study highlights the critical areas where maternal healthcare services are lacking. The analysis has highlighted the importance of physical access to health services in shaping the provision of maternal healthcare services.

Drawing on empirical observations of operation of public distribution system in different states of India, the paper constructs a preliminary game theoretic model. It argues that an effective public distribution must be as universal as possible, delivery mechanism of fair price shops should be reformed, they should be make them commercially viable and that special attention should be paid to PDS at times of high food inflation.
\end{abstract}

Key words: Maternal Health Care Services, Accessibility, Connectivity, Accountability

\footnotetext{
+ UGC-JRF, Department of Geography, The University of Burdwan, West Bengal, 713104, Email: alokanandaghosh04@gmail.com

${ }^{*}$ Corresponding Author

'̇ Assistant Professor, Department of Geography, The University of Burdwan, West Bengal, 713104, Email: brmistri@gmail.com

(C) 2016 Ghosh and Mistri. This is an Open Access article distributed under the terms of the Creative Commons Attribution License (http://creativecommons.org/licenses/by/2.0), which permits unrestricted use, distribution, and reproduction in any medium, provided the original work is properly cited.
} 


\section{Introduction}

Each new-born that dies, each still birth that occurs and each woman who departs her life during pregnancy or childbirth is an unbearable and superfluous loss that should be a matter of grave concern for everyone inclusive of the society and the government (Singh, 2016). While there are numerous factors responsible for these kinds of trouncing events, we focus on those factors that affect the interval between the onset of obstetric complication and its outcome. Rugged, undulating surface along with rough road conditions, excessive transportation cost and inadequate mode of transportation are liable to many of the enroute fatalities, like transit delivery leading to maternal death, miserable obstetric outcome, etc. There is a lack of research on these sorts of transit events. This study, therefore, aims to accomplish the area of en-route causality behind the anguished picture of maternal health care services and maternal health outcome in the study area. Along with the transport and transit factors, provision and quality of care are the important governing factors of a health care system. Again distance, cost and quality alone do not give a full understanding of the utilization of the maternal health care system, unless and until the study is dealing with factors like underserved scenario and accountability of the health care system. Paucity of literature on the said perspectives is the driving forces behind the initiation of the present investigation. The study is again fervent to identify the impact of distance on the status of surveillance and accountability of the maternal healthcare services. The work has been outlined according to the objectives that have been carried out to accomplish the knowledge gaps in the previous surveyed literature.

The study is structured as follows-it begins with a brief background on issues linked to primary healthcare services. This is followed by a discussion on the methodological issues undertaken for this research. Following this, we present our findings under the heading 'Results and Discussions'.

\section{Background}

The primary healthcare services are the most indispensable factor for maintaining population health, especially in rural areas, because it is comparatively less expensive than specialized services and can be provided to the mass on a large scale if properly distributed (Divya et al., 2014). The availability of maternal healthcare services in rural areas of developing countries remains poor because of low availability of human resources (lyengar et al., 2009). The study of accessibility to healthcare has long been of interest to medical geographers and other social sciences (Joseph and Phillips, 1984; cited in Kara \& Egressi, 2013a). Access to healthcare is a multi-dimensional system, including the factors like availability, acceptability, financial accessibility, and geographic accessibility (Blanford et al., 2012; Taiar et al., 2010a). The nature of terrain, road condition, location, aspect, distance having greater influence to measure the degree and status of maternal healthcare services of a given area (Thaddeus \& Maine, 1994a). Accessibility of the healthcare facilities is concerned with the ability of a population to obtain a certain set of healthcare services, which according to Penchansky \& Thomas (1981) and Oliver \& Mossialos (2004) can be grouped into three categories - (a) availability, (b) affordability and (c) geography (cited in Black et al., nd.). Deteriorating roads coupled with inadequate, unaffordable transport make it impossible for the poor to access the health facilities (Mamdani \& Bangser, 2004a). The 3delays model has been used by Thaddeus \& Maine (1994b) to establish the importance of underlying major factors in the utilisation of maternal healthcare services.

Phase I- "delay in deciding to seek care" on the part of the individual, the family, or both; Phase-II-"delay arrival at the health facility"; Phase III-"delay the provision of adequate care" (Thaddeus \& Maine, 1994c: 1091).

Distance shows an inverse relationship behind the utilisation of healthcare services (Buor, 2002a). There are several issues and challenges that make the health policy and infrastructural 
allocation difficult to implement, as these are directly related to the distance to health service and need to healthcare (Murad, 2007). The access to health services is the area to which healthcare infrastructure is directly related and seems to influence the healthcare seeking behaviour of the cohort (Airey, 1989a). There is some literature, which have emphasised road quality as an indispensable factor along with terrain, accessibility and connectivity in the provision, allocation and utilisation of maternal healthcare services (Airey, 1989b; Akhtar \& Izhar, 2010c; Satia et al., 2014). Straight-line distances, driving distances and driving time is strongly linked with each other. Straight-line distances can be used to assess physical access to health services (Taiar et al., 2010b). Substantial geographic variation in accessibility to health service is creating hindrance in the provision of services where seasonal differences in travel route and travel time play a dominant role (Blanford et al., 2012). The lack of transport facilities was reported to be a major problem hindering childbirth at hospitals. Many residents of Birbhum villages are suffering from this problem (Rana et al., 2005).

Situations are even worse in developing part of the Asian countries, like in India. The healthcare delivery system is being influenced by the healthcare seeking behaviour (Lowis and Thomas, 1992; Suchman, 1965; cited in Mondal, 2003a). He has described it as a logical, sequential process. In a study by Neeraja (2014), most pregnant women in the first trimester had reported that they choose the place of Antenatal Care (ANC) according to their conveniences to go to the health centre. They mostly opt for the public preventive care rather than the private curative care (Mondal, 2003b; Park, 2013).

According to Mansourian (Akhtar \& Izhar, 2010b), this structural component of health services deepen the efficacy and efficiency of the services. Another important element of the maternal healthcare system is the accountability and responsiveness regarding the provision of services (Brikenhoff, 2003; George, 2003). "Accountability in health system is seen to ensure appropriate allocation, disbursement, utilisation and monitoring of financial resources, including publicly accessible information" (Mamdani \& Bangser, 2004b: 146). The social issues and stigma often mark the accountability issue for those people belonging to the deprived section of the society. Thus, it is more applicable to sexual, reproductive and maternal health along (Miller, 2014).

To be accountable implies a formal relationship and...it also implies a prior act of delegation direct from one party to another. It is important that the accountability frameworks focus on formal lines of authority outlining: (i) areas of responsibilities, (ii) clear expectations, (iii) required reporting, and (iv) performance evaluation (Manitoba Health and Healthy Living, 2009: 2).

The fairness and accountability in a healthcare system governs through the relationship between population, provider, payer relationship in context of health status, financial and responsiveness of the system (The World Bank Health Nutrition and Population, 2013-2018). The provision and behaviour of work force are the two important guiding factors behind any healthcare services. Geographical situation, sub-regional variations in resources often determine the provision of work force and their behaviour (Bevan \& Charlton, 1987).

\section{Objectives, Methodological Issues and Location of the Study Area}

\section{Objectives}

The objectives are set forth as follows:

- To quantify the accessibility and connectivity status of the study area.

- To assess the influence zone of each healthcare institution.

- To detect the scenario of inadequacy of service provisions.

- To identify the status of accountability of Maternal Healthcare Services (MHCSs), and 
- To establish the interrelationship between accessibility and connectivity with the prevailing MHCSs.

\section{Hypotheses of the Study}

To establish the core concept of the research as to whether the level of accountability of the maternal healthcare services is being influenced by the prevailing road accessibility and connectivity or not, the following null hypotheses have been formed.

- $\mathrm{H}_{0}=$ The Accessibility Index (AI) have no impact on the level of accountability of the MHCSs (that there is no significant correlation between the two variables)

- $\mathrm{H}_{0}=$ The Direct Connectivity Index (DCl) have no impact on the level of accountability of the MHCSs (that there is no significant correlation between the two variables)

\section{Methods and Materials}

This research is based on an empirical retrospective cohort survey, which was conducted in the Sub-Centres (SCs), Primary Healthcare Centres (PHCS) of the respective C.D. Block, Murarai-II. The retrospective study, also called a historic study, is a medical research study in which, the investigator collects data from past records and does not take the follow up approach, as is the case with a prospective study. Concisely, in the retrospective study, all the events-exposure and subsequent outcome are considered to have occurred already in the past. We collected the data now to find out the possible risk factors. The time to complete a retrospective study is only as long as it takes to collect and interpret the data. The study area comprise with 29 Sub-Centres (SCs), four Primary Healthcare Centres (PHCS) and one Block Primary Healthcare Centre (BPHC). To identify the influence zone of each healthcare centres (SCs, PHCs and BPHC), Global Positioning System (GPS) points have been taken accordingly. The influence zones have been portrayed through buffer analysis. One, three and five kilometres of buffers have been created considering the influence or feed zone of each healthcare centres. Then it has been overlaid to the elevation map of the Murarai-II block to see whether the elevation is affecting the influence zone of the healthcare facilities. For the formation of Digital Elevation Model (DEM) , Advanced Space born Thermal Emission and Reflection (ASTER) Global Digital Elevation data (October, 2011) of Birbhum District have been taken and the portion of the Murarai-II Block have been clipped to serve the purpose. The statistical analyses have been performed using Microsoft Office Excel, 2007 and SPSS, Version 15 (SPSS Inc., Chicago, Illinois, USA, 2009) and spatial distributions have been mapped through ArcGIS, Version 9.3 (Environmental Systems Research Institute, Esri Developers Summit, 2008). The data regarding the scenarios of inadequacy and the accountability of the maternal healthcare services have been taken through the response of the health workers (ANMs and ASHAs) of each Sub-Centres and Primary Healthcare Centres. The significance levels between the road network and provision of maternal healthcare services have been tested through Student t-Test and $\mathrm{p}$-value.

\section{The Study Variables}

(A) The scenario of inadequacy in MHCSs has been identified through different indices, like(a) Concentration Index of underserved population, (b) Underserved Population Density, (c) Concentration Index of villages without ASHAs, and (d) Underserved Scoring Index. The parameters that have been considered to assess the indices are stated as follows: (a) Concentration Index of Underserved Population - (i) Total population under the approved (by the Block Primary Healthcare Centre) influence zone of each SubCentres, (ii) No. of Accredited Social Health Activist (ASHA) being sanctioned to each respective Sub-Centres. (b) Underserved Population Density - (i) Total Underserved Population of each gram panchayat (GP), (ii) Area $\left(\mathrm{km}^{2}\right)$ of respective GP. (c) Concentration Index of Villages without ASHA - (i) Total no. of villages under the authoritative influence zone of each Sub- Centre (SC), (ii) No. of ASHA being 
sanctioned to each respective SC, (iii) No. of villages without ASHA. (d) Underserved Scoring Index - (i) Percentage of Underserved population to total population of the GP, (ii) Percentage of Villages and without ASHA, (iii) Percentage of Villages having Half Part Served, (iv) Percentage of Villages Situating $>2 \mathrm{~km}$ from the SC, (v) Percentage of Population have to cross $>2 \mathrm{~km}$ to reach the Sub-Centres..

(B) To identify the accountability of the MHCS's different parameters were taken into account, these are - (I) Visit of medical officer (MO) once in three months, (II) Visit of medical officer (MO) once in six months, (III) Never visit of MO, (IV) Name-based tracking of all pregnant women for assured delivery services, (V) Identify high risk pregnancies and management, (VI) Timely referral of high-risk cases, (VII) Pre-birth preparedness training, (VIII) Call the Ambulance, (IX) Accompanying the cohort to the institution, (X) Promoting institutional delivery, (XI) Tracking missed and left-out cases, (XII) Timely Post Natal Care (PNC) visit immediate after institutional and home delivery, (XIII) Conduction of Village Health Nutrition Day (VHND), (XIV) Coordination with Integrated Child Development Scheme (ICDS), (XV) Home to home for once in annual, (XVI) Health and nutrition education for all cohort.

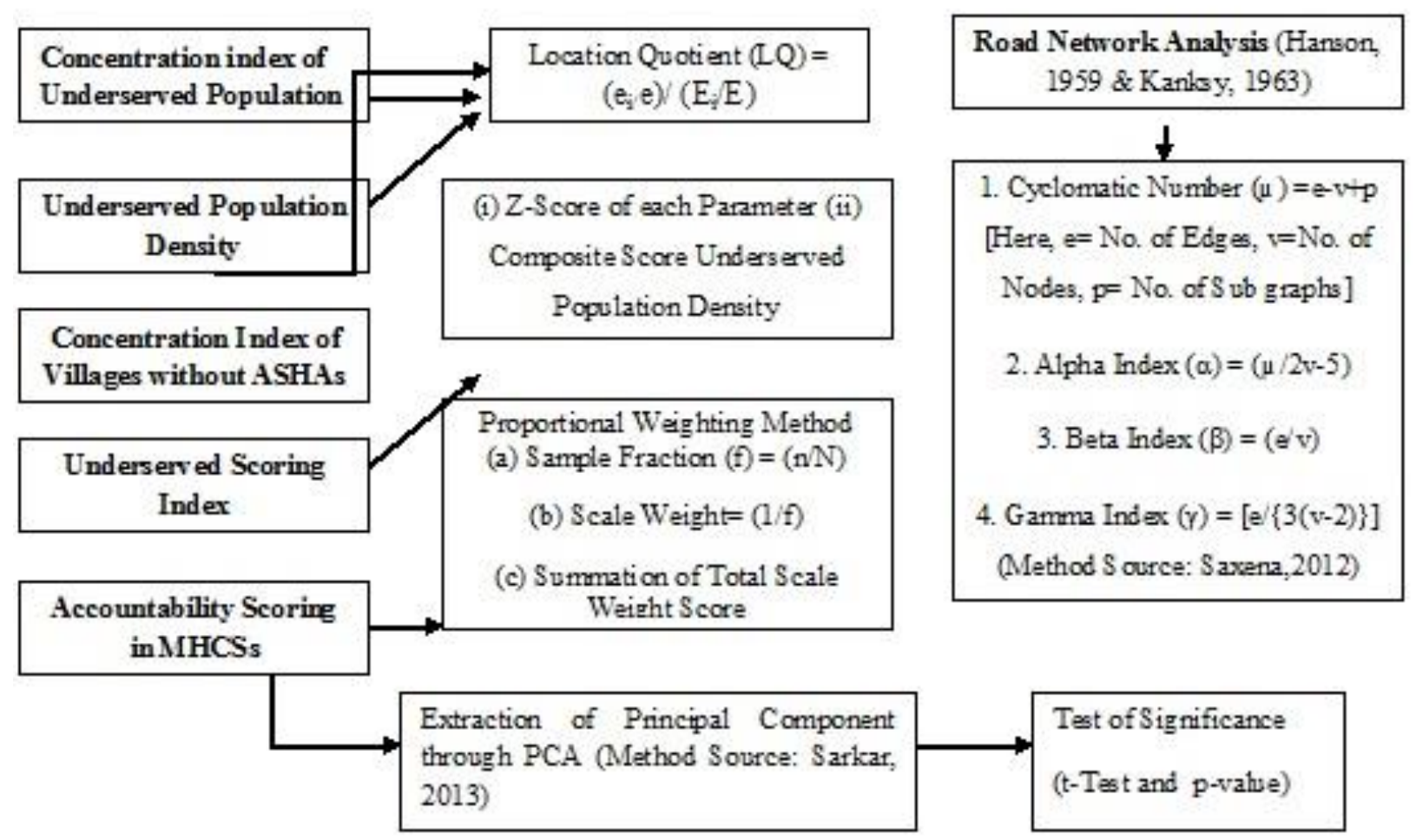

Figure 1: Flow Chart of Methods and Methodology

\section{The Study Area}

The C. D. Block Murarai-II lies in the northern part of the Birbhum District, West Bengal, with an extension from $24^{\circ} 20^{\prime} 33^{\prime \prime} \mathrm{N}$ to $24^{\circ} 33^{\prime} 35^{\prime \prime}$ $\mathrm{N}$ and $87^{\circ} 50^{\prime} 41^{\prime \prime} \mathrm{E}$ to $87^{\circ} 58^{\prime} 35^{\prime \prime} \mathrm{E}$. The Block is located at a distance of $95 \mathrm{kms}$. from district headquarters, Suri (Population Census, Govt. of India, 2011). It is bounded on the North by C. D. Block Murarai-I and district Murshidabad, on the East by district Murshidabad, on the West by C. D. Block Murarai-I, and on the south by police station Nalhati (District Statistical Handbook, Birbhum, 2011). The block is highly populated amongst 19 other blocks of the district with 239770 population (Report from SCs during Field Survey, 2015; $\mathrm{CMOH}$ office, 2015), with a population density of $1143 / \mathrm{km} 2$, more than the District's $707.60 / \mathrm{km} 2$, comprising an area about $185.33 \mathrm{~km} 2$ (Population Census, 2011). There are nine-gram 
panchayats (GPs) and 65 mouzas in the study Healthcare Centres and one Block Primary area with 29 Sub-Centres, four Primary Healthcare Centre (Paikar).

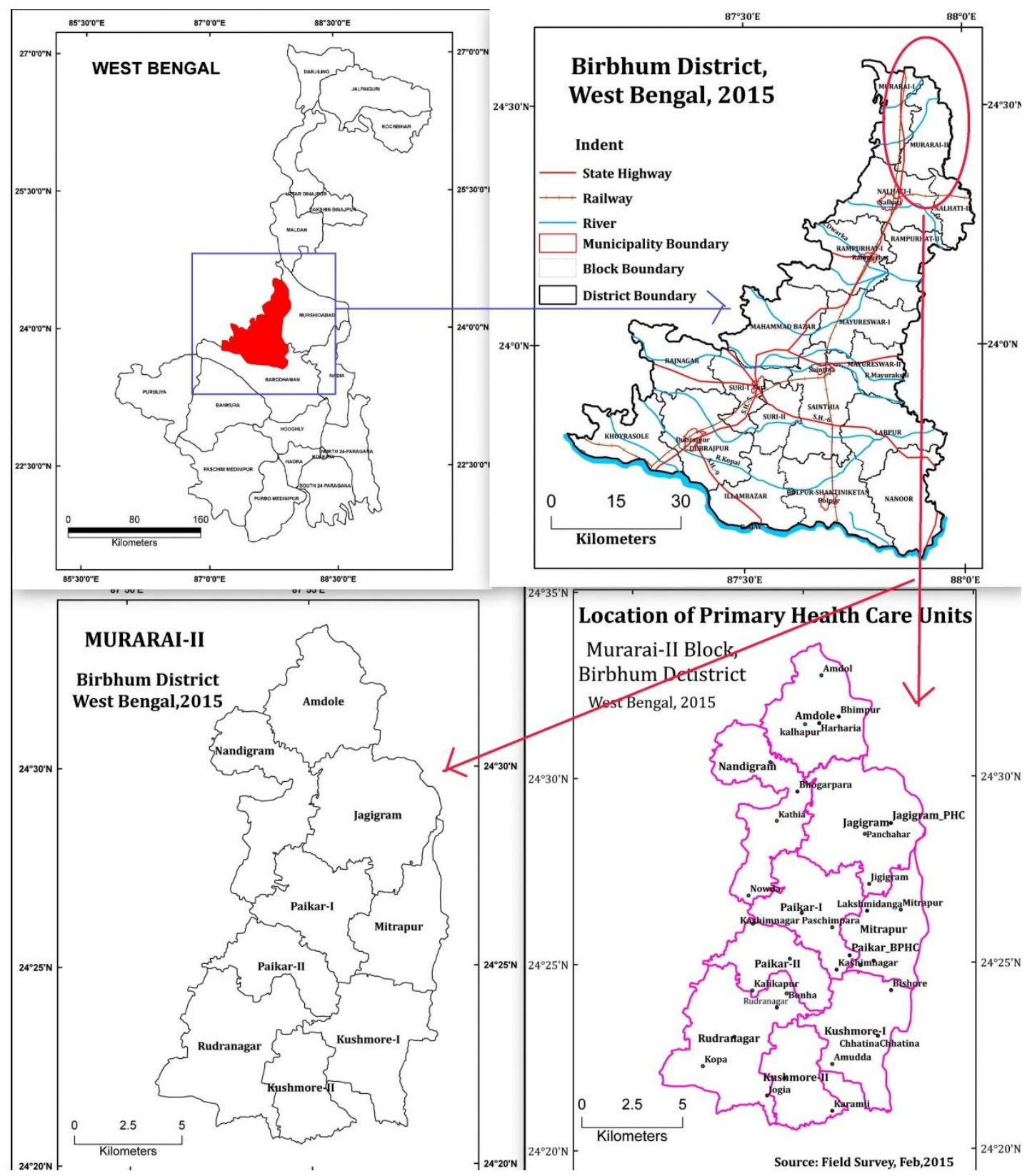

Figure 2: Location Map

(Source: GPS Points of the Institutions have been taken during Field Survey, 2015)

\section{Results and Discussions}

\section{Morphometric Alignment of the Study Area}

The entire eastern part of Birbhum district comes under the lower elevation zone $1<40$ Mt.), Murarai-II is sharing this part of Birbhum. In Murarai-II, the entire North, and NorthEastern part cover an elevation range between 10-30 Mt. being distributed within the GPs like-
Amdol, Jajigram, Nandigram, and part of PaikarI gram panchayat. The southern part is characterised by comparatively higher elevated topography as 30-40 Mt. and above, where the gram panchayats like South-East of Paikar-II, and the entire Mitrapur, Rudranagar, Kushmore-I and II are situated. 


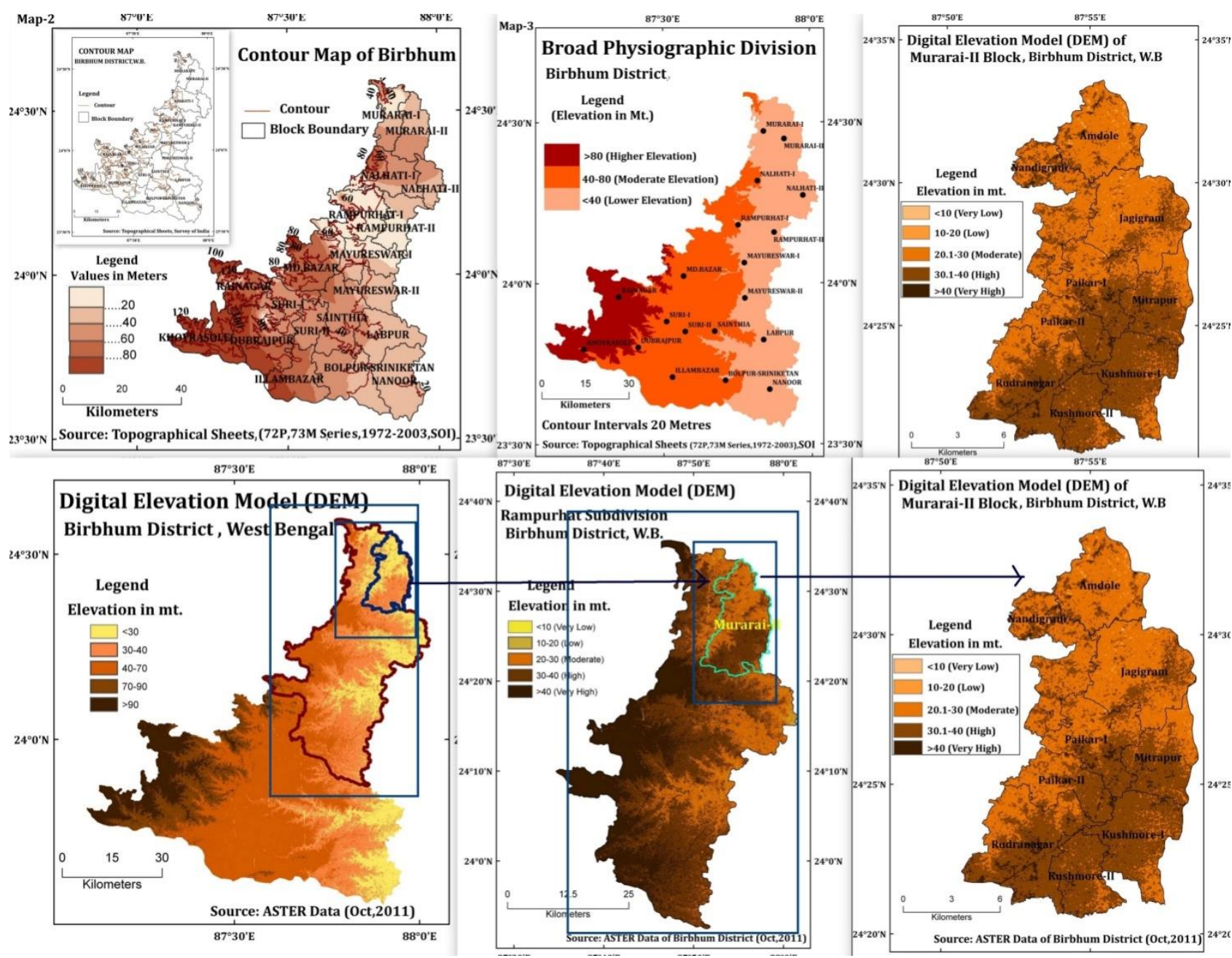

Figure3: Morphometric Alignment of the Study Area

(Source: Authors)

Prevailing Road Network Accessibility and Connectivity Status

Accessibility to the road network facility centres is the highly indispensable factor to control the utilisation of maternal healthcare services, as in most cases, pregnant women, belonging to resource poor region, often suffered from delivery related complications because of less and timely access to transport to reach the facility centre. Proximity to the service and protecting health is the key concern of the issue of healthcare service system; it is to correct the "health impairments" (Akhtar \& Izhar, 2010). While connectivity and network structure of the study area are illustrated in Table 1 using cyclomatic number $(\mu)$ and Alpha, Beta and Gamma indices; using the parametersShimbel Index, Koning Number and Direct Connectivity Index, Table 2 portrays the accessibility and connectivity characteristic of the study area.
One of the most important measures of connectivity of a network is the Alpha Index ( $\alpha)$, ranges between 0 to 1 . It is a measure of connectivity, which evaluates the number of cycles in a graph in comparison with maximum number cycles. The higher the index, the greater is the degree of connectivity in the network. Here the index value, 0.15 is portrayed very low degree of connectivity. Beta Index $(\beta)$ measures the level of connectivity in a network and is expressed by the relationship between the numbers of links (e) over the number of nodes (v). For tree and simple networks, $\beta<1$ and for a connected network with one cycle, $\beta=1$. More complex network has a value greater than 1 . Thus, here the Beta Index $(\beta)$ is representing a complicated network structure with value 1.11 . The connectivity as measured by Gamma Index $(\gamma)$ varies from a set of nodes having no interconnection to the one in which every node has an edge connected to other nodes in the graph. It is a 
measure of connectivity that considers the relationship between the number of observed links and the numbers of possible links. The numerical range of the index is 0 to 1 . Here, the value 0.48 indicates lower connectivity, where the numbers of non-interconnected set of nodes are greater than the nodes, which have an edge connected to another node in the circuit. The Cyclomatic number is a different way of measuring connectivity. In a disconnected tree-type network the index is to be ' 0 '. Here, the number 2 indicating low to moderate connectivity status (Table 1 ).

It is evident that the most accessible gram panchayats are- Paikar I (15) and II (16) have scored the higher Shimbel Index value, where the Amdol and entire Kusmore-I are showing lower accessibility with a value of 25 and 31 respectively (Figure 4). The Koning number describes the degree of centrality of any node of a network. In the study area the Koning number is low in Paikar-II (3) and then in Paikar-I (4). These are signifying central places of Murarai-II. On the other hand, the most distant GPs of the block are-Kushmore-I and Amdol with a Koning value of 6 for each. Nandigram, Jajigram and Kushmore-II are having the value of 5 and the rest GPs are ranging between 4 to 5 . The Direct Connectivity Index is high for the area like- Paikar-I and II, Jajigram, part of Rudranagar, as two major roads are intersected in these areas, likeChatra-Rudranagar-Jajigram road and MuraraiMitrapur road. The intersecting point of these two major roads of the block is lying in Hiyatnagar, part of Paikar-II gram panchayat, thus the area Paikar-II is occupying the first raw in the centrality and direct connectivity index.

\section{Table 1: Connectivity and Network Structure of the Study Area}

Cyclomatic Number $(\mu)$

Alpha Index ( $\alpha)$

Beta Index ( $\beta$ )

Gamma Index ( $(\gamma)$
2
0.15
1.11
0.48

Source: Authors, 2015

Table 2: Accessibility and Connectivity Characteristic of the Study Area

\begin{tabular}{c|c|c|c|c} 
Category & Parameters & $\begin{array}{c}\text { Maximum } \\
\text { Values }\end{array}$ & Minimum Values & $\begin{array}{c}\text { Average } \\
\text { Values }\end{array}$ \\
\hline \multirow{2}{*}{$\begin{array}{c}\text { Connectivity } \\
\text { and }\end{array}$} & Shimbel Index & 31 & 15 & 21.11 \\
\cline { 2 - 5 } Accessibility & Koning Number & 6 & 3 & 4.78 \\
\cline { 2 - 5 } & Direct Connectivity Index & 4 & 1 & 2.22 \\
Source: Authors, $\mathbf{2 0 1 5}$ & \multicolumn{4}{|l}{}
\end{tabular}

\section{Scenario of Inadequacy in Maternal Health Care Services (MHCSs)}

The availability of health centres within 3 to 5 kilometres of the neighbourhood has a strong effect on the concentration of served and underserved population in the study area. It is evident that the influence zones of those SubCentres' are smaller, which are situated in comparative higher elevation, like Kushmore-I and II (Figure 5). Though Rudranagar is also lying in the same elevation (Figures 3 and 6), but the feed zone of the particular sub-centres is comparatively higher than the others. The reason is that (i) Rudranagar is the only Primary
Healthcare Centre (PHCs) amongst the four (Kathia, Bhimpur, Jajigram and Rudranagar), which serves $31.03 \%$ of the total sub-centre and $14 \%$ of the total block population (2, 39,770 ), (ii) it is the only Primary Healthcare Centre which is used to provide delivery facilities at least more than 20 deliveries in a month, and (iii) the only one Type-B Primary Healthcare Centre within the region. Although since September 2015, this facility has been interrupted by some underlying political annoyance and service inadequacy, which had 
huge repercussion on the health system Rudranagar as well as of the areas that comes under the influence zone of the Primary Healthcare Centre (Figure 5). This Primary Healthcare centre is covering entire nine subcentres, comprising three entire gram panchayats, which are- Rudranagar, KushmoreI and II.

To identify the underserved population concentration, two main parameters have been taken into account. These are (i) total population under the approved (by the Block Primary Healthcare Centre) influence zone of each Sub-Centre; and (ii) number of ASHA being sanctioned to each respective Sub-Centre. According to the Support Mechanism for ASHA:

One of the key strategies under National Rural Health Mission (NHM) is having a Community Health Volunteer i.e. ASHA (Accredited Social Health Activist) for every village with a population of 1000 . The Government of India in matter of selection and training of ASHA has issued detailed guidelines. The States have been given the flexibility to relax the population norms as well as the educational qualifications on a case to case basis, depending on the local conditions as far as her recruitment is concerned (National Health Mission, 2014).

The general norm of selection, that is one ASHA for 1,000 population has been relaxed to one ASHA per 1,200 habitation by the Block Primary (mostly obstetric

health) of Healthcare Centre (BPHC) of Murarai-II block, because of the excessive population load $(2,22,033$, Population Census, 2011) of the block, sharing, $7 \%$ of the total Birbhum district's population. The block have 1143/sq. km population density, which is more than the district's population density (707.60/sq. km), according to the population census, 2011. Insufficiency in the number of health workers to accommodate the prevailing population is the key issue behind the underserved status of the study area.

The underserved population concentration is high ( $L Q=>1.2)$ in those areas which are lying in the last cluster of accessibility and connectivity index, like- Kushmore-II, Amdol (Figure 6). Here distance is playing a major role in the distribution of underserved population. Many of the studies using records from health facilities, their findings often indicate that highest proportion of users are located close to the facility and the proportion of users declines as the radius increases (Thaddeus \& Maine, 1994, p. 1094d). Apart from these two areas, Paikar-II is showing higher position in the underserved population concentration status. This is because of excessive population pressure, as the area is lying in the second category in the population density map (Figure 7). Regarding the underserved population density rank, Paikar-II is sharing the place in highest cluster (see, Figure 7).

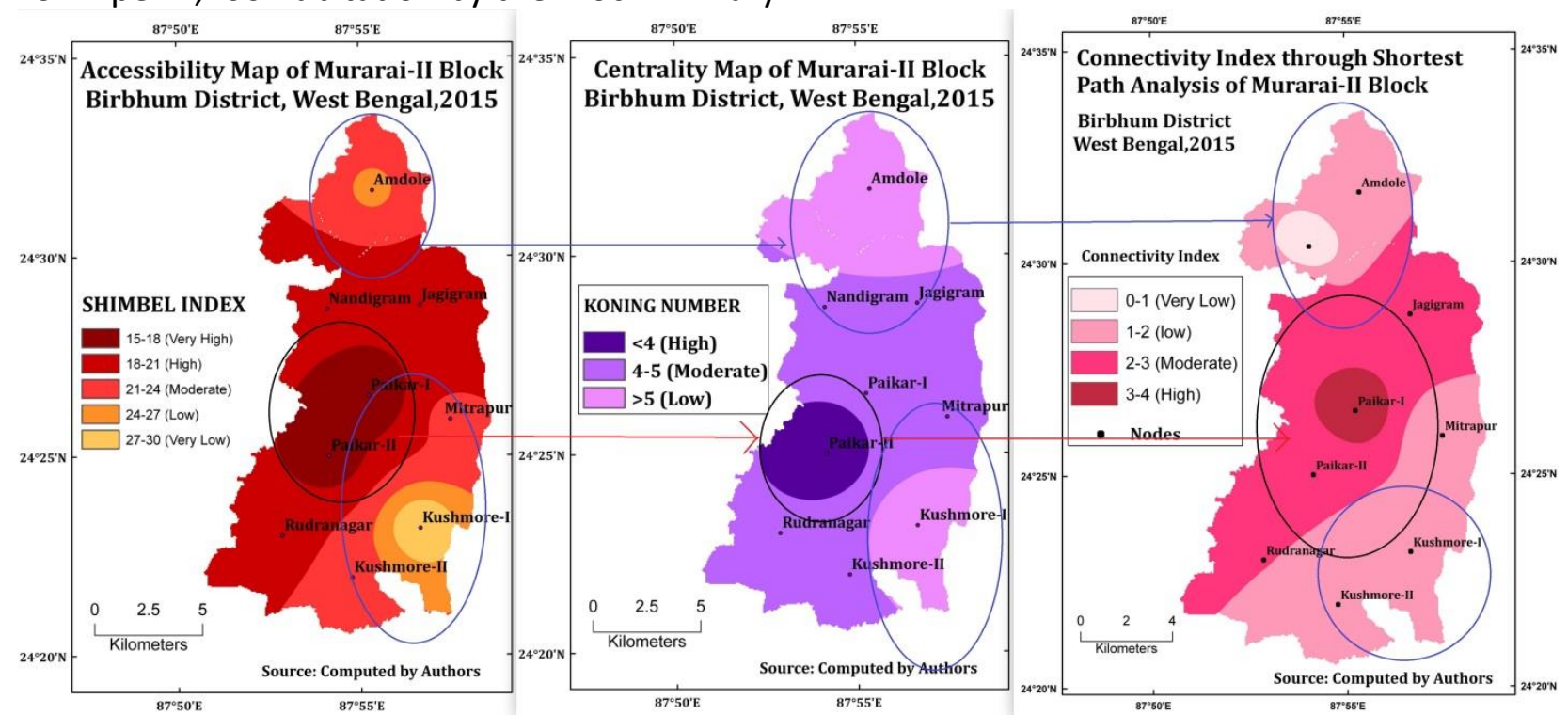

Figure 4: Accessibility and Connectivity Characteristic of the Study Area (Source: Authors) 


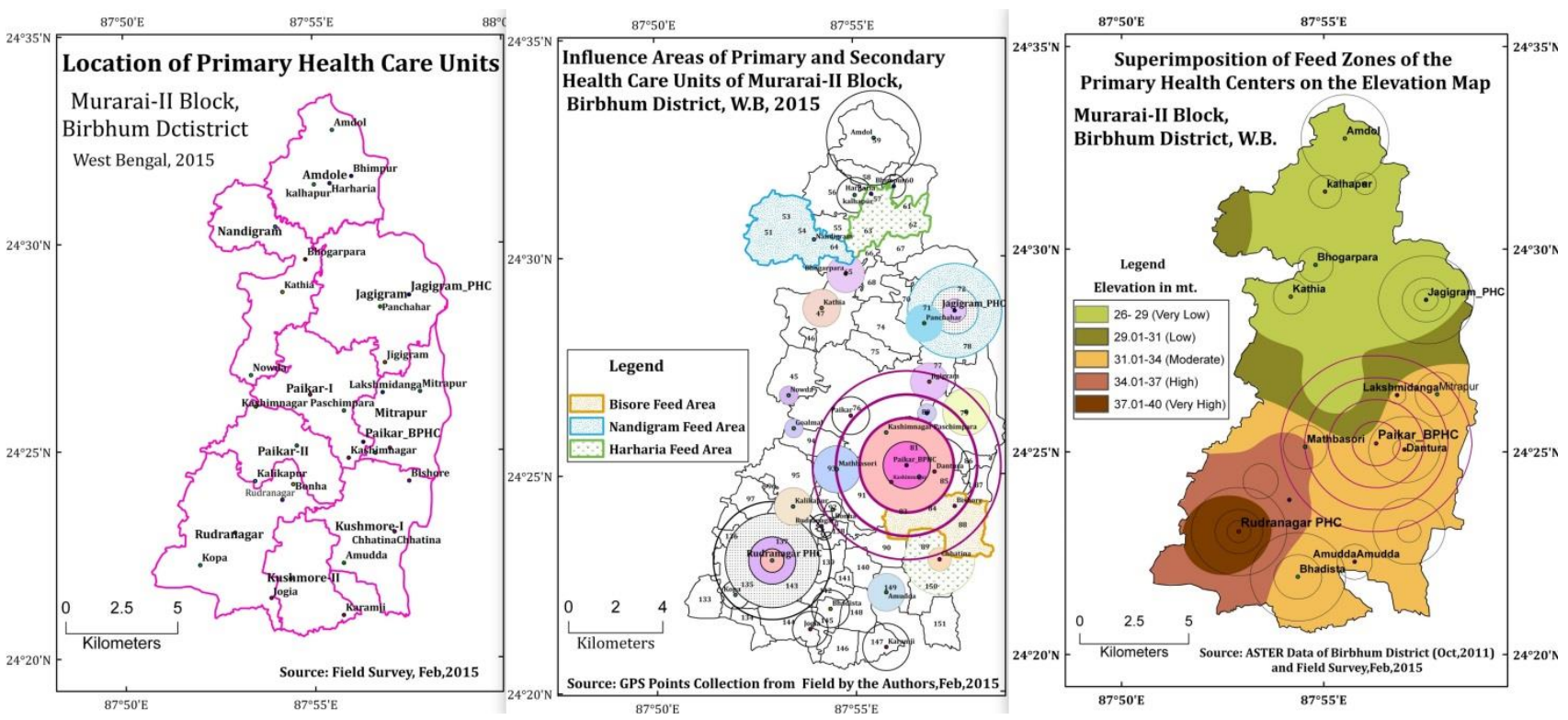

Figure 5: Influence Areas of Health Centres

(Source: Authors)

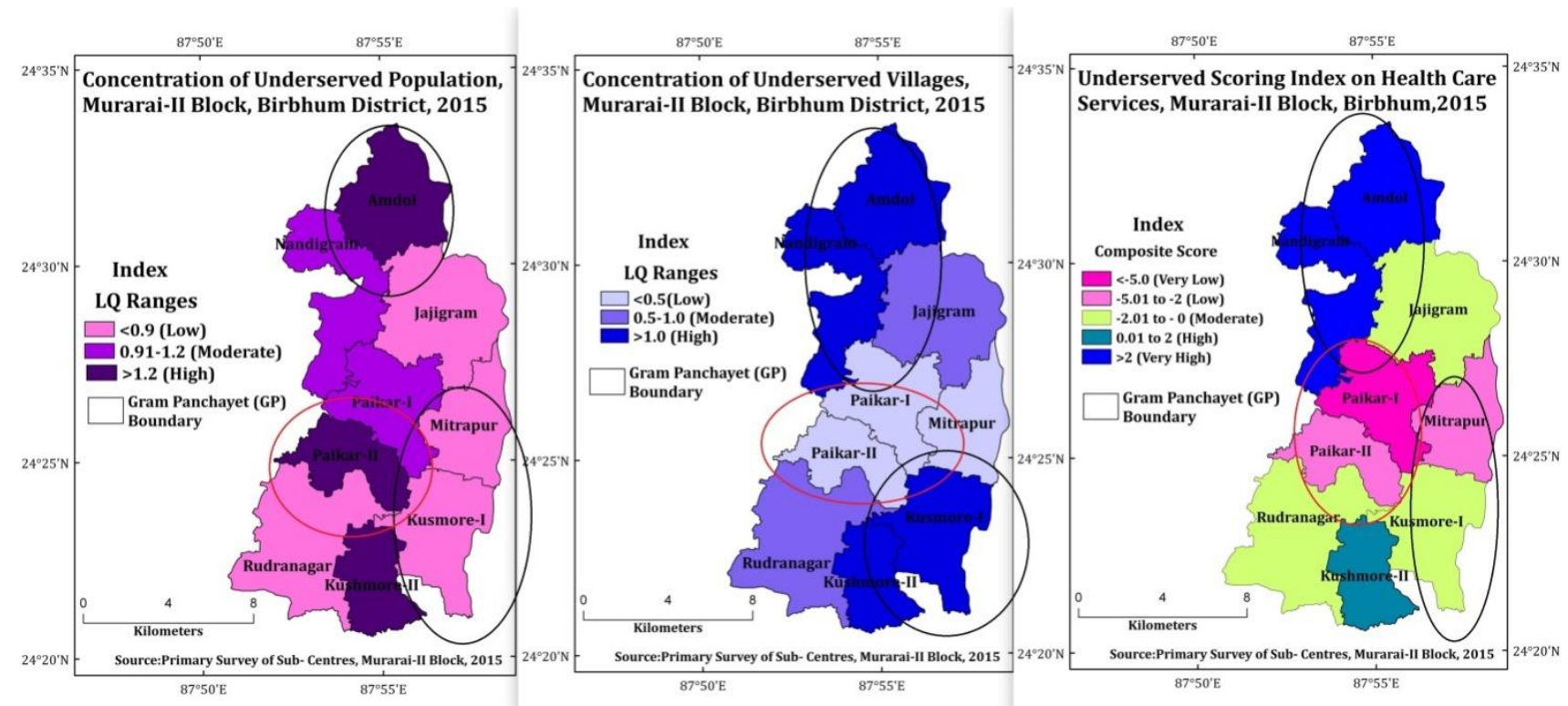

Figure 6: Scenario of Inadequacy in Maternal Healthcare Services

(Source: Authors) 


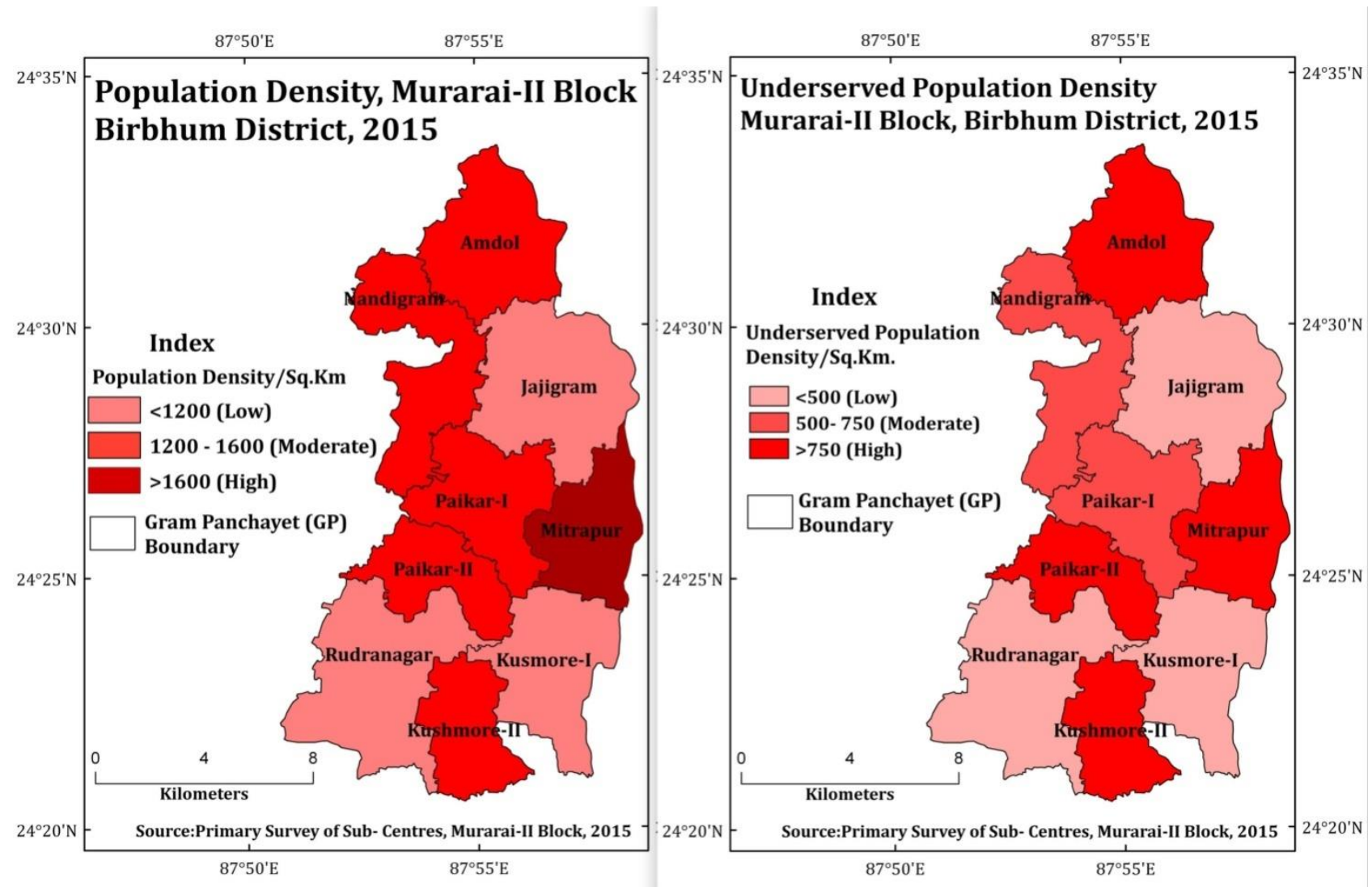

Figure 7: Population Density

(Source: Authors)

\section{Provision of Maternal Healthcare Services (MHCSs) and its Accountability}

Enhanced accountability is often considered as an important element in improving health system performance. The spirit of accountability is answerability; being answerable means having the compulsion to answer questions regarding decisions and our actions (George, 2003; Miller, 2014; \& Brinkenhoff, 2003).

Figure 8 is depicts the fact that with the increase of the distance from the Block Primary Healthcare Centre to the sub-centre, the Accountability Score is decreasing gradually. Paikar-I and Rudranagar are in the "very high" position ( $>72$ Score) in the accountability index, because of its proximity to the Block Primary Healthcare Centre (Figure 9). But for Rudranagar, the situation is getting worse day by day. The delivery service has been stopped in recent past because some nuisance took place between the governing authority and local inhabitants. This is of course in accordance to the opinions of the locals and health workers. But the Block Primary Health care
Centre bears a lackadaisical attitude to improve the situation for the betterment of Rudranagar Primary Health care Centre. Even the Block Primary Healthcare Centre has withdrawn the Medical Officer (MO) of the Primary Health care Centre to accommodate the paucity in the labour. According the Sub-Centre and Primary Health care Centre (Rudranagar), the medical officer (MO) of Block Primary Health care Centre do not visit the Primary Health care Centre on a regular basis. He used to visit once in three months, that too after repeated request is being made by the Primary Health Care Centre. These undesirable issues are largely because of the increasing distance from Block Primary Health care Centre $(>12 \mathrm{~km})$ and low to moderate accessibility index (Figure 4). There is a strong inverse relationship between accessibility score and accountability score 0.75 (Figure 8), as the increase in the value of Shimble Index and Koning Number denotes decrease in accessibility. On the other hand, the relationship is positively proportional (0.56) in case of relationship between direct connectivity index and accountability index of 
MHCS provision. As in case of direct connectivity, more is the value means less is the connectivity. The accountability is negatively influenced by the distance and this picture could be seen in Kushmore-I. Frequent transfer of Auxiliary Nurse Midwives (ANM) is the common scenario for the Sub-Centres of Kushmore-I gram panchayat. In a very recent past (September 2015), the field survey has come out with a surprising situation in the Kushmore-I gram panchayat regarding the transfer of Auxiliary Nurse Midwives. All the three Sub-Centres of Kushmore-I gram panchayat - Amuddya, Chhatina and Bisore, have experienced frequent transfer of Auxiliary Nurse Midwives to the adjacent district of Murshidabad within a tenure of six months. All of them were first Antenatal Midwives. According to the local people's view, health workers, coming from outside the village, are not willing to work in such a remote place characterised by inadequate transportation with rough road. It is because these blocks do not have direct connectivity with the major two

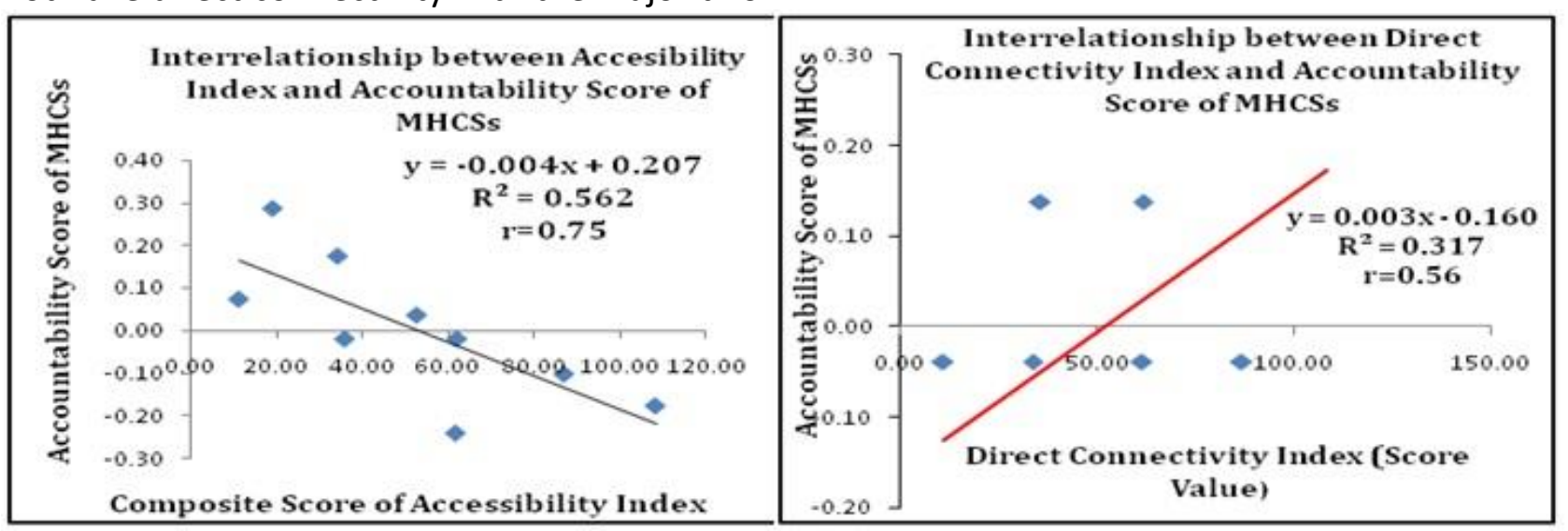

Figure 8: Interrelationship between Accessibility and Direct Connectivity Index with Accountability Score

(Source: Authors) roads of this block, which are Murarai-Mitrapur road and Chatra-Rudranagar-Jajigram road. Another picture of inadequate surveillance could be seen in Bhimpur primary health care centre, situating in Amdol G.P., $18 \mathrm{~km}$ away from the block primary healthcare centre (Paikar). This primary healthcare centre is lying in a distress condition for a long period, without any bed or infrastructure (Figure 10). Distance is probably the main constraint behind this meagreness in accountability.

These incidences are indicating towards the scenario of accountability along with the inadequate quality of care. As being mentioned by Thaddeus \& Maine (1994e) that there are two mechanisms through which quality of care affects the utilisation of services are the outcome variables (e.g. effectiveness of the system and accountability) and input variables (variables regarding service received, e.g. staff strength, attitude, facility procedure, availability and provision of supply and efficiency). 


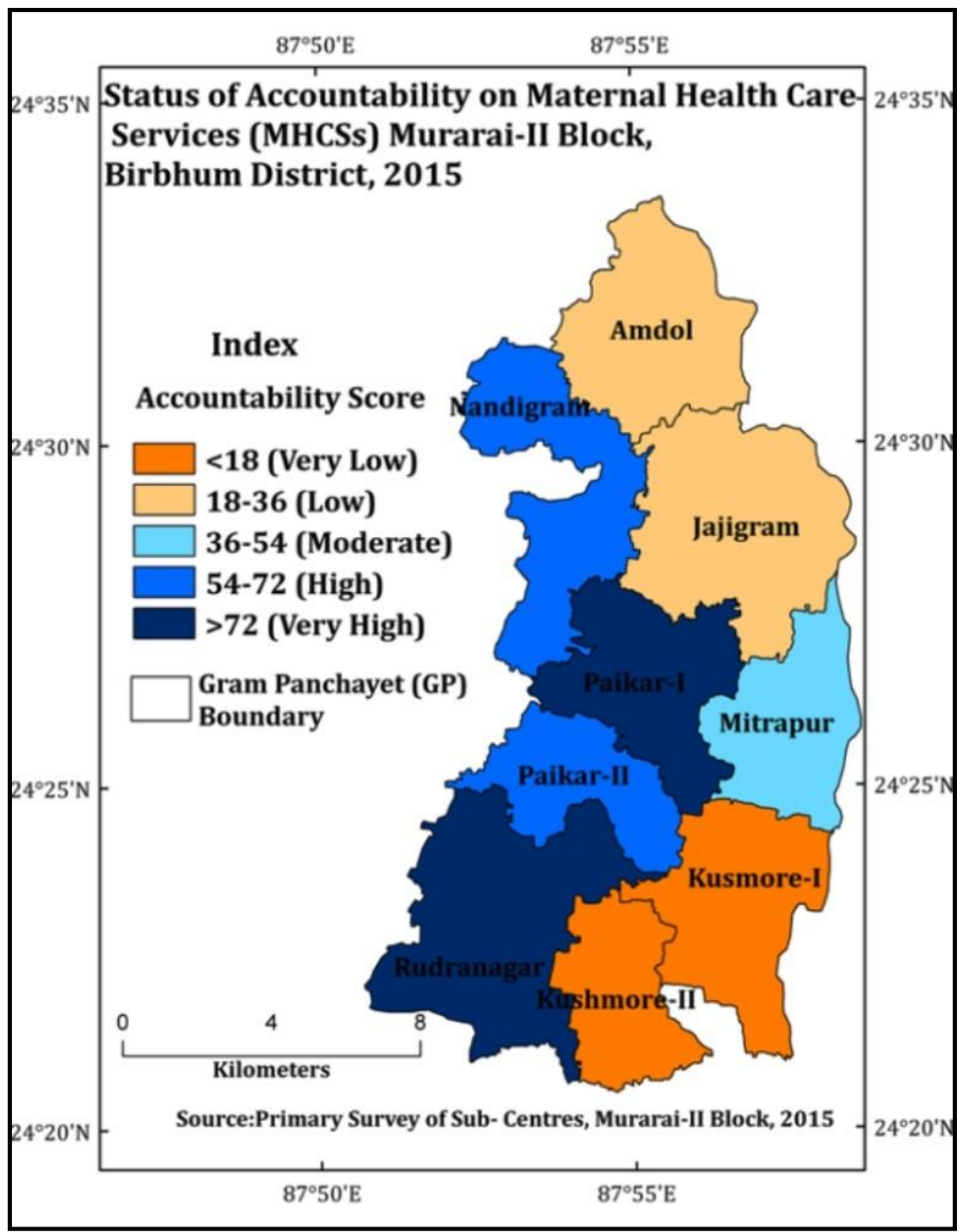

Figure 9: Status on Accountability of Medical Healthcare Services

(Source: Authors)

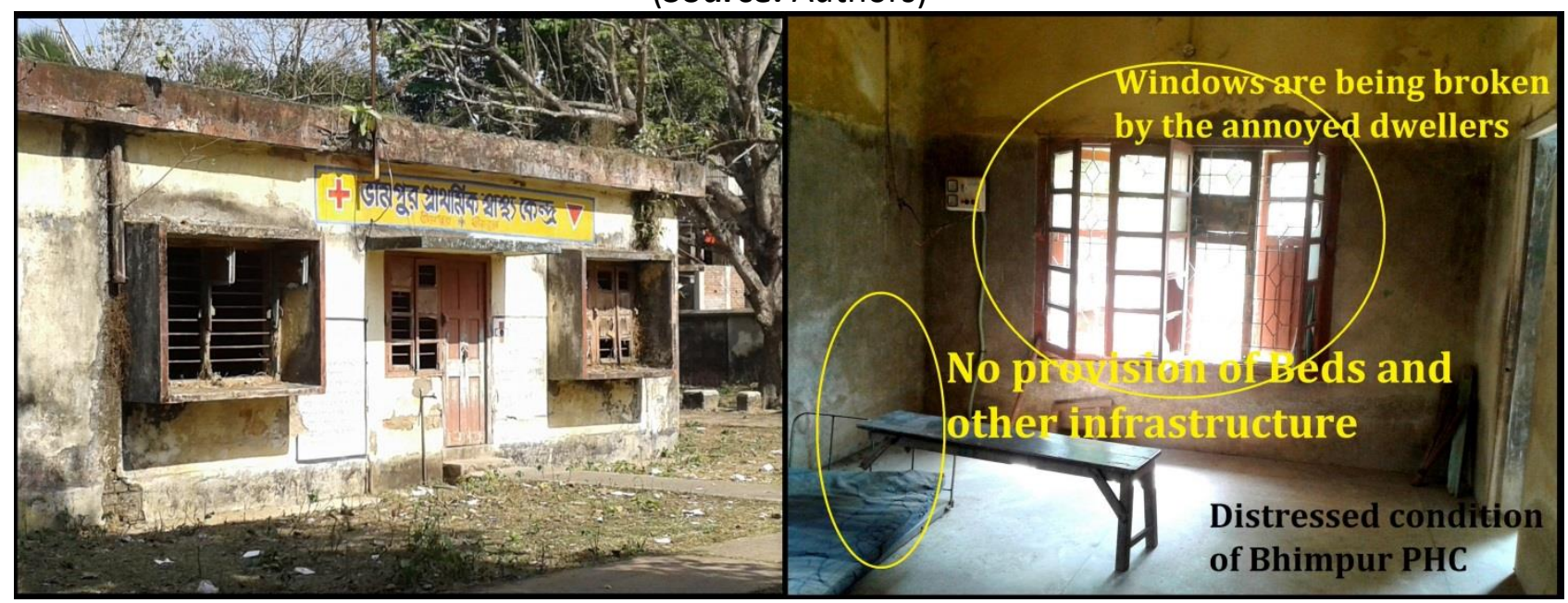

Figure 10: Distress Condition of Bhimpur Primary Healthcare Centre (PHC), Bhimpur, Murarai-II, 2015 (Source: Authors) 


\section{Interrelationship between Accessibility and Direct Connectivity Index with Accountability Score}

To extract factors from the data sets the Principal Components Analysis (PCA) method, the most common form of factor analysis, have been chosen. The criteria considered to determine the number of factors to be retained for further analysis was suggested by Harman in 1976 (Hirama et al., 2010). The correlation coefficient (by product moment method) between all the 16 variables are worked out and has been arranged in the form correlation matrix. The PCA is a procedure to convert a set of observations of possibly correlated variables into a set of values of linearly uncorrelated variables called principal components (Kothari \& Garg, 2014). From the correlation matrix, it is evident that tracking-based activities are the prime dominant factors to identify the level of accountability in the maternal healthcare services (MHCSs) in the Murarai-II Block. (IV) Name based tracking of all pregnant women for assured delivery services, (XI) tracking of missed and left-out cases, and (XVI) healthnutrition education for all cohort are significantly correlated with the variable like (I) visit of medical officer once in three months (Table 3). It is indicating that lower transparency and educational awareness of the cohort has worsened the situation of service utility in the study area. Thus, access to information and education are the prerequisite to ensuring the effective participation in monitoring the provision of health services (Mamdani \& Bangser, 2004c). Apart from this, (XI) tracking of missed and left-out cases are positively correlated with (VI) timely referral of high-risk cases. (XVI) Health-nutrition education for all cohorts is significantly associated with the parameter; (V) identifies high-risk pregnancies and management, at the same time. Thus, proper visit of medical officer and providing health-nutrition related education to the entire cohort can significantly improve the undesirable scenario of maternal healthcare services in the region. Identification and tracking of high-risk pregnancy can also be done voluntarily by the health workers.

The number of the principal component is less than the number of original variables. This transformation is defined that the first principal component, that is (XII) timely PNC visit immediate after institutional and home delivery (0.93), accounts for the largest variability in the dataset along with (V) identify high risk pregnancies and management (0.92). Apart from these factors there are certain dominant factor in the system like (IV) name based tracking of all pregnant women for assured delivery services (0.86) and (VII) Pre-birth preparedness training (0.82).

In the first PCA, with $49.67 \%$ explanation, variables IV, V, VII and XII, all the other variables are showing positive relationships. These are prime dominant factors in the system of accountability in MHCSs. In this context, more emphasis should be given on the variables like (IV) name-based tracking of all pregnant women for assured delivery services, (V) identify high risk pregnancies and management, (VII) pre-birth preparedness training and (XII) timely PNC visit immediate after delivery, for further development in the accountability of maternal healthcare services. Only the variable III (never visited by medical officer) is reflecting the negative effect in the system as the loading value is $(-0.4)$. In the second loading, the system is getting explained $24.03 \%$. Here the system dominancy have been transferred to variables (III) never visit of Medical Officer (0.83), (XIII) conduction of VHND (0.90) and (XV) home to home for once in annual (0.90). Whereas the prime factors of first PCA are showing negative occurrence in the second stage of loading (Table 4). Thus, it is clear from the analysis that the system is being mostly influenced by the variables of first PCA and these components are directly getting affected by the under servility and shortage of staff in the facilities. Insufficient numbers of medical and nursing personnel at a facility necessarily lead delays in patients' receiving the care they need. 
Table 3: Interrelationship between the Factors of Maternal Healthcare Services and its Level of Accountability (Pearsonian product moment correlation matrix, $R$ ) in Murarai-II, Birbhum (2015)

\begin{tabular}{|c|c|c|c|c|c|c|c|c|c|c|c|c|c|c|c|}
\hline & II & III & IV & V & VI & VII & $\begin{array}{c}\text { VII } \\
\text { I }\end{array}$ & IX & $x$ & XI & XII & XIII & XIV & $x V$ & XVI \\
\hline I & $\begin{array}{ll}1 & 0 . \\
& 27\end{array}$ & $\begin{array}{c}- \\
0.3 \\
4\end{array}$ & $\begin{array}{l}0.7 \\
1^{*}\end{array}$ & $\begin{array}{c}0.6 \\
6\end{array}$ & 0.55 & $\begin{array}{c}0.5 \\
1\end{array}$ & $\begin{array}{c}0 . \\
06\end{array}$ & $\begin{array}{c}0.3 \\
8\end{array}$ & 0.31 & $\begin{array}{c}0.97 \\
* *\end{array}$ & 0.53 & 0.19 & 0.22 & 0.19 & $\begin{array}{c}0.84 \\
* *\end{array}$ \\
\hline II & 1 & $\begin{array}{l}0.7 \\
8^{*}\end{array}$ & $\begin{array}{c}0.4 \\
8\end{array}$ & $\begin{array}{l}0.7 \\
5^{*}\end{array}$ & 0.41 & $\begin{array}{c}0.6 \\
3\end{array}$ & $\begin{array}{l}0 . \\
28\end{array}$ & $\begin{array}{l}0.7 \\
0^{*}\end{array}$ & 0.05 & 0.32 & 0.59 & $\begin{array}{c}- \\
0.07\end{array}$ & $\begin{array}{c}0.89 \\
* *\end{array}$ & -0.1 & 0.46 \\
\hline III & & 1 & $\begin{array}{c}- \\
0.3\end{array}$ & $\begin{array}{c}- \\
0.5\end{array}$ & -0.3 & $\begin{array}{c}- \\
0.5\end{array}$ & $\begin{array}{l}0 . \\
3\end{array}$ & $\begin{array}{c}- \\
0.6\end{array}$ & 0.36 & -0.4 & -0.3 & 0.6 & -0.6 & 0.6 & -0.4 \\
\hline IV & & & 1 & $\begin{array}{c}0.6 \\
6\end{array}$ & $\begin{array}{c}0.86 \\
* *\end{array}$ & $\begin{array}{l}0.7 \\
2^{*}\end{array}$ & $\begin{array}{l}0 . \\
33\end{array}$ & $\begin{array}{c}0.5 \\
5\end{array}$ & 0.15 & $\begin{array}{c}0.85 \\
* *\end{array}$ & $\begin{array}{c}0.85 \\
* *\end{array}$ & 0.26 & 0.43 & 0.26 & $\begin{array}{c}0.76 \\
*\end{array}$ \\
\hline v & & & & 1 & 0.35 & $\begin{array}{c}0.6 \\
1\end{array}$ & $\begin{array}{l}0 . \\
46\end{array}$ & $\begin{array}{l}0.7 \\
9^{*}\end{array}$ & 0.48 & 0.65 & $\begin{array}{c}0.83 \\
* *\end{array}$ & 0.35 & $\begin{array}{c}0.80 \\
* *\end{array}$ & 0.35 & $\begin{array}{c}0.79 \\
*\end{array}$ \\
\hline VI & & & & & 1 & $\begin{array}{l}0.7 \\
7^{*}\end{array}$ & $\begin{array}{l}0 . \\
23\end{array}$ & $\begin{array}{c}0.2 \\
7\end{array}$ & $\begin{array}{c}- \\
0.07\end{array}$ & $\begin{array}{c}0.70 \\
*\end{array}$ & 0.59 & 0.12 & 0.21 & 0.12 & 0.49 \\
\hline $\begin{array}{l}\text { VI } \\
\text { I }\end{array}$ & & & & & & 1 & $\begin{array}{l}0 . \\
42\end{array}$ & $\begin{array}{l}0.7 \\
1^{*}\end{array}$ & 0.17 & 0.60 & $\begin{array}{c}0.77 \\
*\end{array}$ & 0.27 & 0.59 & 0.27 & 0.35 \\
\hline $\begin{array}{l}\text { VI } \\
\text { II }\end{array}$ & & & & & & & 1 & $\begin{array}{c}0.3 \\
8\end{array}$ & $\begin{array}{c}0.80 \\
* *\end{array}$ & 0.07 & 0.62 & $\begin{array}{c}0.89 \\
* *\end{array}$ & 0.37 & $\begin{array}{c}0.89 \\
* *\end{array}$ & 0.20 \\
\hline IX & & & & & & & & 1 & 0.28 & 0.41 & $\begin{array}{c}0.82 \\
* *\end{array}$ & 0.20 & $\begin{array}{c}0.87 \\
* *\end{array}$ & 0.20 & 0.38 \\
\hline$x$ & & & & & & & & & 1 & 0.19 & 0.41 & $\begin{array}{c}0.86 \\
* *\end{array}$ & 0.18 & $\begin{array}{c}0.86 \\
* *\end{array}$ & 0.32 \\
\hline XI & & & & & & & & & & 1 & 0.63 & 0.17 & 0.26 & 0.17 & $\begin{array}{c}0.85 \\
* *\end{array}$ \\
\hline $\begin{array}{c}\mathbf{X I} \\
\mathbf{I}\end{array}$ & & & & & & & & & & & 1 & 0.51 & $\begin{array}{c}0.69 \\
*\end{array}$ & 0.51 & 0.62 \\
\hline $\begin{array}{l}\text { XI } \\
\text { II }\end{array}$ & & & & & & & & & & & & 1 & 0.12 & $\begin{array}{c}1.00 \\
* *\end{array}$ & 0.21 \\
\hline $\begin{array}{l}\text { XI } \\
\text { V }\end{array}$ & & & & & & & & & & & & & 1 & 0.12 & 0.39 \\
\hline $\begin{array}{l}x \\
V\end{array}$ & & & & & & & & & & & & & & 1 & 0.21 \\
\hline$x$ & & & & & & & & & & & & & & & 1 \\
\hline
\end{tabular}

Note: * Correlation is significant at the 0.05 level (2-tailed); ${ }^{* *}$ Correlation is significant at the 0.01 level (2-tailed), (Source: Authors) 
Table-4: Interrelationship between the Factors of Maternal Healthcare Services and its Level of Accountability (Extraction of principal components with cumulative percentages of variance) in Murarai-II, Birbhum (2015)

\begin{tabular}{|c|c|c|c|c|c|c|c|c|c|c|c|c|c|c|c|c|}
\hline PCA & I & II & III & IV & V & VI & VII & VIII & IX & $x$ & XI & XII & XIII & $\begin{array}{l}\text { XI } \\
\text { V }\end{array}$ & $X V$ & $\begin{array}{c}X V \\
\text { I }\end{array}$ \\
\hline $1(49.67$ & 0.7 & 0.7 & - & 0.8 & 0.9 & 0.6 & 0.8 & 0.5 & 0.7 & 0.4 & 0.7 & 0.9 & 0.4 & 0.7 & 0.4 & 0.7 \\
\hline$\%)$ & 2 & 0 & 0.4 & 6 & 2 & 5 & 2 & 4 & 9 & 4 & 7 & 3 & 3 & 2 & 3 & 7 \\
\hline $\begin{array}{c}2 \\
(24.03 \\
\%)\end{array}$ & $\begin{array}{l}- \\
0.2\end{array}$ & $\begin{array}{l}- \\
0.4\end{array}$ & $\begin{array}{r}0.8 \\
3\end{array}$ & $\begin{array}{r}- \\
0.1\end{array}$ & $\begin{array}{r}- \\
0.0 \\
4\end{array}$ & $0 . \overline{-}$ & $\begin{array}{r}- \\
0.1\end{array}$ & $\begin{array}{r}0.7 \\
4\end{array}$ & $0 . \overline{-}$ & $\begin{array}{r}0.7 \\
8\end{array}$ & $\begin{array}{r}- \\
0.2\end{array}$ & $\begin{array}{r}0.1 \\
2\end{array}$ & $\begin{array}{r}0.9 \\
0\end{array}$ & 0.3 & $\begin{array}{r}0.9 \\
0\end{array}$ & $\begin{array}{r}- \\
0.1\end{array}$ \\
\hline
\end{tabular}

Source: Authors

This shortage is often not only a matter of staff numbers but also a matter of competence and surveillance (Thaddeus \& Maine, 1994f). Improvement in these factors can definitely change the face of the total system.

\section{Relevance of Interrelationship between Road Networks and Accountability on Maternal Healthcare Services}

Interrelationship between road networks and accountability on maternal healthcare services has been calculated using the formula Student " $\mathrm{t}$ " test (Das, 2008).

The formula reads as: $T=\left[r \times\left\{\sqrt{(n-2)} /\left(1-r^{2}\right)\right\}\right]$

From the significance test it is evident that accessibility index have significance correlation (0.75) with the accountability index of MHCSs. As the $p$-value is $<0.05$ and t-value ( 3 ) is greater than the tabulated value $(2.37)$ at $0.05 \%$ significance level. Thus the null hypothesis has been rejected as the $t_{0.05}<3$ at degree of freedom (df) $=7[(9-2)=7]$. It means that accessibility index have direct significant impact on the accountability as the p-value is $<0.05$. On the other hand, there is not that much significant correlation between direct connectivity index and accountability score of the maternal healthcare services, as the $t_{0.05}>$ 1.78 at $\mathrm{df}=7$ and the $p$-value is $>0.05$. Thus to improve the status of maternal healthcare services and its level of accountability the governing body should focus on connecting the remote areas with increased number of connecting nodes to the main road. The accessibility would increase with the increased value of Gamma Index $(\gamma)$. As in the study area, the Gamma Index $(\gamma)$ is portraying higher aggregation of non-interconnected network than interconnected network.

Table 5: Table for Significance Test

\section{Independent}

Variable

\section{Dependent Variable}

Correlation Coefficient

( $r)$

\section{Computed Value} "t" value at 0.05
$\%$ significance

p-value

\begin{tabular}{llcccc}
\hline $\begin{array}{l}\text { (a) Accessibility } \\
\text { Index }\end{array}$ & $\begin{array}{l}\text { Accountability } \\
\text { Score of }\end{array}$ & 0.75 & 3 & & 0.019 \\
\cline { 1 - 1 } $\begin{array}{llll}\text { (b) Direct } \\
\text { Connectivity Index }\end{array}$ & MHCSs & 0.56 & 2.37 & \multirow{2}{*}{0.118}
\end{tabular}

\section{Source: Authors, 2015-'16, Source of Tabulated Value (Sarkar,2013)}

\section{Conclusion}

The investigation found that: (i) the influence zone of the maternal healthcare service centres is directly influenced by the accessibility of different health centres in the study area, (ii) it is again determined by the variation in population load of each healthcare centres; (iii) the concentration of underserved population increases substantially with the increase of distance from the respective sub-centres. Areas that are reflecting this scenario are Kushmore-I, Kushmore-II and Amdol; (iv) the level of 
accountability also decreased with increased distance from the Block Primary Healthcare centre. Gram panchayats like- Kushmore-I and II, Amdol and Jajigram are falling in this category.

The following steps can be a taken to bring adequacy in the maternal healthcare service system of Murarai-II block: (i) increase the accessibility and connecting these areas with main road can be a major input to alter the deprived situation of the GPs, (ii) provision of health worker maintaining the population pressure, local demand and grassroot level aspiration, not by retaining only the rules of Indian Public Health Standard (IPHS), (iii) preventing frequent transfer of Auxiliary Nurse Midwives (ANMs), (iv) grassroot level coordination between the health workers belonging to different sector of National rural Health Mission (NRHM), like Integrated Child Development Scheme (ICDS) workers and ASHA health workers, (vi) supervising and monitoring the Medical Officers' (MO) performance regarding provision of services in the SC and PHC, (vii) further increasing the number of accredited health professionals with midwifery skills working in well-equipped facilities within rural communities is of critical importance if the women of Murarai-II are to have healthier pregnancy and safer delivery. The scenario of less accountability can be prevented by scalingup different monitoring interventions in the geographically distant areas. Accelerating interventions to improve the maternal healthcare service and overall maternal health status would require government to ensure sufficient, equity-based provision of services adequate and skilled human resources along with essential transportation system. All these needed to accommodate the high-quality service, especially when the obstetric emergencies arise in the fragmented settings of vulnerable population. As the survival and good, accountable healthcare are the right of every mother despite of her socio-economic belongings.

\section{References}

Airey, T. (1989). The Impact of Road Construction on Hospital Inpatient Catchments in the Meru District of Kenya, Soc Sci Med. US National Library of Medicine. National Institute of Health, 29 (1), pp. 95-106. Retrieved from http://www.ncbi.nlm.nih.gov/pubmed/274093 2

Akhtar ,R., \& Izhar, N. (2010). Global Medical Geography, Jaipur: Rawat Publication, (ISBN-81316-0198-6).

Bevan, G.,\& Charlton, J. (1987). Making Access to Healthcare More Equal: The Role of General Medical Services. British Medical Journal,295 (6601), BMJ, pp. 764-767.

Black, M., Ebener, S., Aguilar, P.N., Vidaurre, M. \& Morjani, Z.E. ( $n$ d). Using GIS to Measure Physical Accessibility to Healthcare, World Health Organisation (WHO). Retrieved from http://www.researchgate.net/publication/2287 28167Using GIS to measure physical accessibility to healthcare Blanford, J.I., Kumar, S., Luo.W. \& MacEachren.A.M. (2012). It's a Long, Long Walk: Accessibility to Hospitals, Maternity and Integrated Health Centers in Niger. International Journal of Health Geographics. 11 (24). pp. 3-15.

Brinkenhoff, D. (2003). Accountability and Health Systems: Overview Framework and Strategies. Partners for Health Reform plus. Retrieved from

https://www.google.co.in/Accountability+and+ Health+Systems:+Overview\%2C+Framework\%2 C+and+Strategies

Buor, D. (2002). Distance as a Predominant Factor in the Utilisation of Health Services in the Kumasi Metropolis, GeoJournal, 56 (2), Springer, pp. 145-157.

Das, N.G. (2008). Statistical Methods, New Delhi. 2 : Tata McGraw-Hill Publising Company Ltd. (ISBN 10: 0-07-026351-5. 451-456). District Statistical Handbook, Birbhum (2011). Government of West Bengal. Kolkata.

Divya, S. Tali, J.A., \& Chandrashekara, B. (2014). Delineation of Primary Healthcare Services in Chamarajanagara Taluk: A Spatial Analysis. Journal of International Academic Research for 
Multidisciplinary. 2 (1) (ISSN: 2320-5083.494503).

George, A. (2003). Accountability in Health

Services: Transforming Relationships and

Contexts. The Harvard Center for Population and Development Studies, 13 (1), pp. 1-16.

Retrieved from

http://www.who.int/management/partnership s/accountability/accountabilityhealthservicespd f.pdf

Hirama, M.V., Toledo, F.A.L., Junior, E.C., Costa, K.B., \& Quadros, J.P. (2010). Q-Mode and R-

Mode Factor Analysis in Quantitative Studies of Microfossils of the Late Quaternary in

Sediments from the Brazilian Continental Margin. University of São Paulo, Oceanographic Inst., Lab. Paleoceanography of the South Atlantic (LaPAS), pp. 41-49. lyengar, S.D., lyengar, K., \& Gupta, V. (2009). Maternal health: A Case Study of Rajasthan. Journal of Health, Population and Nutrition. 27 (2), icddr, b. pp. 271-292. Retrieved from http://www.jstor.org/stable/23499529 Kara, F., \& Egresi, I.O. (2013). Accessibility of Healthcare Institutions: A Case Study by Using GIS. International Journal of Scientific Knowledge. 3 (4). pp. 16-27. (ISSN-2305-1493). Retrived from www.ijsk.org Kothari, C.R., \& Garg, G. (2014). Research Methodology: Methods and Techniques, New Age International Publishers (ISBN: 978-81-2243623-5).

Mamdani, M. \& Bangser, M.(2004). Poor People Experiences of Health Services in Tanzinia: A Literature Review. Reproductive Health Matters (RHM), 12 (24), pp. 138-153, Retrieved from http:/www.jstor.org/stable/3776589

Miller, H.D. (2014). Measuring and Assigning Accountability for Healthcare Spending. Center for Healthcare Quality \& Payment Reform. Retrieved from https://www.google.co.in/?gws_rd=ssl\#q= Assigning+Accountability+ Healthcare+Spending Mondal, S.K. (2003). Health Nutrition and Morbidity: A Study of Maternal Behaviour. Development Evaluation Society of India (DESI). Bookwell Publication. New Delhi-110002, India. pp. 1-187. (ISBN:81-85040-69-9).
Monitoba Health and Healthy Living. (2009). Achieving Health System Accountability: Getting there Together. Retrieved from https://www.gov.mb.ca/health/rha/docs/ahsa2 009.pdf

Murad, A.A.( 2007). Creating a GIS Aapplication for Health Services at Jeddah City.Computers in Biology and Medicine. Elsevier Science Ltd., Great Britain. 37. doi:10.1016/j.compbiomed.879-889. Retrieved from

www.intl.elsevierhealth.com/journals/cobm National Health Mission (2014).About Accredited Social Health Activist (ASHA), Ministry of Health \& Family Welfare, Government of India.

Population Census of India (2011). Government of India: Office of the Registrar General \& Census Commissioner, India.

Park, K., (2013). Preventive and Social Medicine. $22^{\text {nd }}$ Edition. M/s Bandarsidas Bhanot Publications. Prem Nagar, Jabalpur-482001 (ISBN No. 978-93-82219-02-6).

Rana, K., Santra, S., Rafique, A., Mukherjee, A. \& Sengupta, A. (2005). The Delivery of Primary Health Services: A Study in West Bengal and Jharkhand. The Pratichi Health Report: With an Introduction by Amartya Sen. Pratichi Trust. Delhi. India.110091 (ISBN 81-88297-03-8. 1108).

Satia, J.K., Misra, M., Arora,R., \& Neogi. S. (2014). Innovation in maternal health: Case study from India. New Delhi : SAGE Publication, (ISBN-978-81-321-1310-2, PB).

Saxena, H. M. (2012).Transport Geography. Jawahar Nagar, Jaipur, India: Rawat Publication, pp. 54-79, (ISBN-81-7033-945-6).

Sarkar, A. (2013). Quantitative Geography:

Techniques and Presentations. Orient Blackswan (ISBN- 978812505266 1).

Singh, P.K. (8 March 2016). Because The Newly Born Deserve Better. The Statesman. Retrieved from

http://www.thestatesman.com/news/opinion/ because-the-newly-born-deservebetter/128402.html.

Taiar A. Al., Clark, A., Longenecker, J. C. \& Whitty, C, J. (2010). Physical Accessibility and Utilisation of Health Services in Yemen. 
International Journal of Health Geographics. 9 The World Bank Health Nutrition and (38), pp. 1-8. doi: 10.1186/1476-072X-9-38. Retrieved from Population. Sector Strategy for MENA. (20132018). Fairness and Accountability: Engaging in http://www.biomedcentral.com/content/pdf/1 476-072X-9-38.pdf. Health System in the Middle East and North Africa. Retrieved from Thaddeus, S. \& Maine, D.(1994). Too Far to http://siteresources.worldbank.org/EXTARABIC Walk: Maternal Mortality in Context. Elsevier HOME/Resources/475644-

Science Ltd. ,Great Britain, 38 (8), 02779536/94, pp. 1091-1110. 1372258525900/English-MENA-HNPStrategy.pdf. 